\title{
BEHAVIOUR OF THE LIVING CELL
}

$\mathrm{T}$ HE papers presented at a conference on "Tissue Culture in Pharmacology" held by the Section of Biology of the New York Academy of Sciences, and the Tissue Culture Association, Duke University, during January 14-16, 1954, have now been published (Ann. New York Acad. Sci., 58 (7), 971-1326; 1954). 'They are concerned with the behaviour of the living cell as a whole, and contain many excellent high-power photomicrographs of living cytoplasm. Parts taken from ciné films show the motion of the various elements in the cytoplasm which is so striking a feature of living cells, not only in tissue culture but also in the whole animal, as the window technique of Algire recently demonstrated. It provides a refreshing and welcome balance in the field of cytology, which has tended to become overloaded with studies on dead cells and particularly with observations exclusively on the nucleus.

A great deal of cytology in the past has been done using fixation methods which dissolve away the cytoplasm so as to render the nucleus more accessible to observation. Since a large part of scientific thought is unconscious-and especially creative thought based on processes of which we are not aware-and since effective intuitive ideas can only be based on past experience (which may be forgotten), the process of looking at cells which have been deprived of their cytoplasm by fixation year after year would tend to create the feeling or intuition that 'there is no cytoplasm'. This is very evident in the writings of some who have subjected themselves to this activity. 'Ihe papers in this collection help to remind us that cytoplasm plays a striking part in the activities of cells.

For some, the development of tissue culture over the past fifty years has been somewhat of a dis appointment. The early promise in the days of Harrison and Carrel led one to expect that many fascinating experiments on living cells would be carried out. These did not appear to any large extent (with some important exceptions), and it was as if the success in getting cells to grow at all was the occasion of so much joy that progress became fixed at that point. The present series of papers represents a departure from this, and one is entertained by some of the advances in the past few years in which the cultured cell is used as a tool for discovering the answers to questions which one has been wanting "to know.

Important advances in culture technique are described by W. R. Earle, G. O. Gey and their colleagues. By a systematic study of the effect of various supporting surfaces for the cells, and of agitating the medium, Earle has succeeded in regularly growing a mass of cells of the order of $1 \mathrm{gm}$. in weight from each inoculation, and, if necessary (after conditioning the medium), from a single cell. This should have repercussions in several directions, especially in biochemistry, where the use of homogeneous populations of tissue cells, instead of mixtures as heretofore, to compare cell with cell should initiate a new biochemistry of the tissue cell and, especially, a biochemistry of cancer.

The development of completely liquid media by Gey and by Earle enables cell suspensions to be handled like solutions, and measured out in aliquots, thus eliminating some of the biological variation in the testing of drugs. These liquid media also enable growth to be measured by the counting of nuclei instead of by the erstwhile indirect method of nucleic acid determination.

It is pleasing to note that the culture of cells appears to have been stripped of much of the semimystic ritual of Carrel and placed on a fairly scientific basis. There seems no reason why these advances in technique should not have been made thirty years ago, except perhaps a paralysing bolief in the need for following a prescribed ritual.

C. M. Pomerat has measured the toxic concentrations of 110 substances on chick and human cultured cells. In view of the known wide differences in susceptibility of various mammalian species to the same drugs, and particularly to carcinogens, and the paucity of information on human material, this method should fill a gap in knowledge without the use of human volunteers and with less variation than with the use of individuals.

The use of tissue culture in the rapid screening of anti-cancer substances is reported in several papers. Here again, the importance of being able to cultivate any kind of tissue cell is emphasized. It is not yet known whether this is possible, and perhaps all the problems are not yet solved. But a favourable therapeutic index obtained on comparing the response to a drug of neoplastic cells with that of fibroblasts has sometimes given disappointing results when the drug is tested in the whole animal, where the more susceptible (but less easily cultured) intestinal epithelium and bone marrow are usually injured. As pointed out in the discussion, it would be better to use these two tissues as controls in culture.

J. T. Syverton and W. F. Scherer deseribe the use of cultured mammalian cells for the assay of viruses and their antibodies. Here again one notes the use of the more readily proliferating tumour cells as indicator, rather than normal cells, though the results appear to be satisfactory.

Several interesting papers describe the effects of various substances on the cytoplasm of cultured cells. While no explanations are yet forthcoming for these effects in terms of chemistry and physics, it is to be hoped that, by supplementing the observations on the more easily handled Protozoa, the comparison should bear fruit.

Pomerat and Gey re-focus attention on the important phenomenon of 'pinocytosis' whereby proteins may enter living cells. This has been almost entirely neglected since first described by W. $H$. Lewis in 1931. W. R. Duryee and J. K. Doherty, and also Pomerat, describe the excretion of visible material from the nucleus into the cytoplasm. The former put forward an interesting theory of mitosis.

While it is not possible to mention all the remarkable findings reported in this conference, many of the contributors seem to be conscious of the effectiveness of their approach and of the impart which it is making on the field: "Gone for ever... is the notion of the fixed rigidity of cells". "What greater contribution could there be to the study of the mechanism of drug action than to pinpoint with precision the part of a cell that may become altered by the drug? This qualitative approach ... is more fruitful than the knowledge, for example, that 
50 per cent of a population of cells is destroyed by a given concentration of a drug", to quote a few of the enthusiasts.

It is not the function of this survey to direct attention to misprints and the like; but the statement on p. 1224 that DNA is the chief chemical component of enzymes seems remarkable.

This report can be thoroughly recommended to biologists and pharmacologists as providing stimulating reading : so much so that it ends with a poem expressing the excitement one may feel at beholding Pomerat's ciné films.

R. J. GOLDACRE

\section{EUROPEAN ASSOCIATION OF EXPLORATION GEOPHYSICISTS}

\section{MEETING AT THE HAGUE}

T

HE seventh meeting of the European Association of Exploration Geophysicists was held at The Hague during December 8-10, 1954, this keing the first occasion when an earlier venue had been revisited. In the three years since the inaugural meeting there, the membership has grown from its anticipated strergth of about one hundred and fifty to a present strength of more than eight hundredan indication of the very active European interest in exploration geophysics. With the president, J. Goguel, in the chair, the proceedings began with a short business meeting and an opening address by Prof. Vening Meinesz. The technical meeting included the presentation of twenty-two papers, nine dealing with seismic, seven with gravity, three with electrical and three with magnetic methods. This distribution does not fully correspond with that of exploration effort between the various methods which, in terms of numbers of field parties, has been quoted recently by Germain-Jones ${ }^{1}$ as seismic 50 , gravity 18 , electrical 24 and magnetic 8 per cent, out of a total of some two hundred and thirty parties based on Europe.

Four of the seismic papers described theoretical approaches to field problems, the first by Y. d'Erceville (France), dealing with the velocity of propagation of longitudinal waves in muds. The observed velocity in such materials is often lower than that of either the solid or liquid constituent, and using a simple mathematical model he showed that such a velocity might be expected. Unfortunately, the theory also predicts a velocity, intermediate between those of the constituents, which is not observed in practice, and there was some criticism of the completeness of the chosen model. A. Stein (Germany), in attempting to determine the applicability of the reflexion method to mining problems in Siegerland, had calculated the energies to be expected in longitudinal and transverse waves reflected from siderite veins of various thicknesses. In a more purely theoretical approach to a similar problem, J. Baumgarte, H. Menzel and O. Rosenbach (Germany) dealt with the reflexion of longitudinal waves at a thin layer lying between media of differing velocities. The frequency spectrum and the energy/time relation. ships were discussed both for sinusoidal plane waves and for an incident prolse of arbitrarily chosen form. Although necessarily somewhat limited by the initial assumptions, this was felt to be a very promising step in the investigation of changes of seismic pulse wave-forms. In a further paper on reflexion sur- veying, W. Brauch (Germany) considrred the traveltime curves with particular reference to the possibility of determining velocity distribution.

Three papers were concerned with the more practical aspects of seismic surveying. W. M. Jones and A. T. Dennison (Great Britain) described a portable geophone, designed for long-distance refraction surveys, which has a natural frequency of $2 \mathrm{c.} / \mathrm{s}$.; while there is some doubt whether this low frequency is required, experimental evidence on the subject is indecisive. The discussion on a protractor, designed by J. Schoeffier and E. Diemer (Germany) to facilitate the computation of refraction results, showed that many computers devise such instruments for the solution of their most frequent problems ; apart from those described at the meeting, instruments of similar type though differing in detail have been described elsewhere ${ }^{2}$. For several years, multiple geophone groupings have been used in reflexion surveying to minimize the background noise due to the shot, and H. Richard and M. Rimbaut (France) gave the results of a quantitative field study of the improvement obtained with various linear arrays; this was found to depend, approximately, on the square root of the number of geophones.

A. M. Selem (Italy) gave a comprehensive description of the instrumental and interpretative techniques required for a reflexion survey in a coastal region of Southern Abruzzi, an area characterized by a heavily eroded topography. The use of special vehicles and field techniques has enabled the survey to be mainly truck-borne in spite of the steep gradients encountered. Variations in the near-surface layers and the rapid changes of surface elevation required a detailed investigation of the requisite corrections; although the results have not yet been checked by drilling, it is thought that the techniques applied have been very successful. At the present stage of geophysical prospecting, it is somewhat unusual to hear a new method proposed. In this case, M. Matschinski (France) suggested that measurements of the seismic ground unrest could yield information on the underlying geological structure. Assuming that the seismic background is random in nature, he has applied statistical methods to show that measurements of shear strain and of the particle velocity at the surface are related to the depth and character of the geological formations. While certain instrumental and field problems can be envisaged in the practical application of such a method, it remains an interesting suggestion for the practical use of what are otherwise, like telluric currents in electrical prospecting, merely unwanted background noise.

In the gravity section, three authors were concerned with improved techniques of interpretation. G. C. Colley (Great Britain) discussed the variations in elevation correction factor required to correct readings to the datum level, with special reference to its variation across geological boundaries and structures. Formulæ were given for the case of dipping beds together with a general discussion of the anomalous effects which may result over anticlines and near outcrops, although it was agreed that application of the results would require some prior knowledge of the general geological picture. F. Sumi (Yugoslavia) was concerned primarily with a rather different application, the determination of the depth of an ore-body when its shape may be assumed. K. Jung (Germany) has derived a formula, suitable for numerical computations, for the topographical correction of gravity measurements; this is analogous 